\title{
The St George Rainway: building community resilience with green infrastructure
}

\author{
J. T. Welsh \& P. Mooney \\ University of British Columbia, Canada
}

\begin{abstract}
Central to global climate change and central to the profession of landscape architecture is the element: water. The St George Rainway offers a new opportunity to be a demonstration project for the City of Vancouver, Canada, where the city and its community of Mount Pleasant act as collaborators with design, construction, and maintenance of a project with water in the public realm. The voluntary engagement in the physical transformation of one's community can provide opportunity for a growth in social cohesion. Subsequently, this growth can improve the conditions that fostered the bonds and bridges within that community that inspired the initial engagement. Green infrastructure, when considered through this lens, has a reciprocal relationship with social cohesion, where the improvement of one feeds the improvement of the other. This model could therefore provide both a resilient option for physical development of land and for social development of community for neighbourhoods by encouraging more interaction among neighbours and with their local public realm.

Keywords: landscape architecture, sustainable development, stormwater, green infrastructure, social cohesion, socioecological resilience, ecosystem services.
\end{abstract}

\section{Introduction}

In recent decades many fields have attempted to develop methods and practices that contribute to global sustainability. The field of landscape architecture is one profession well-situated to advance efforts of sustainable development. With landscape architecture, there has been a dramatic improvement in the design and 
use of urban storm water management systems. These green infrastructure systems treat water at the surface - they purify it, store it, and recharge it, rather than delivering it in its most polluted state to the nearest body of water. To date, the emphasis of this type of green infrastructure has been ecological. The ability of urban stormwater systems to support cultural values and resilient communities, while providing ecological benefits, has been largely overlooked.

This study explored the potential of green infrastructure to expand into a sociological realm. This work explores how to focus the social cohesion of a neighbourhood to provide the energy needed to establish a piece of green infrastructure. As with the ability of natural systems to self-replicate, the ability of green infrastructure to maintain or increase its conceived functionality is best designed by including members of a subject community throughout all phases of its development and maintenance. Such an approach lessens the need for deep pockets on behalf of municipalities and creates a positive feedback loop where volunteer stewardship grows one's attachment to place, which grows subsequent contributions from community.

Social cohesion refers to "a state of affairs concerning both the vertical and the horizontal interactions among members of society as characterized by a set of attitudes and norms that includes trust, a sense of belonging and the willingness to participate and help, as well as their behavioural manifestations" [1]. Green infrastructure is an approach "to maintain healthy waters, provide multiple environmental benefits and support sustainable communities [that] uses vegetation and soil to manage rainwater where it falls. By weaving natural processes into the built environment, green infrastructure provides not only stormwater management, but also flood mitigation, air quality management, and much more" [2]. Regarding social cohesion, green infrastructure can be considered a "behavioural manifestation" of a community in its efforts to increase the presence of bonds and bridges, subsequently creating opportunity for growth of that community.

This paper outlines a perspective for focusing the voluntary engagement in the physical transformation of one's community by using green infrastructure as the tool and the characteristics of resilient communities as the framework. The utilization of public open space can provide opportunities for communities to foster interaction among neighbours. At the global scale, this work should be considered as a narrative that expresses the power that lies in replication of similar initiatives throughout a city to create vibrant communities that encourage interaction between neighbours. It is through the pivotal step of building bonds and bridges within community that can shape vibrant and resilient cities to help plan for and face the inevitable climate and resource challenges of the future.

\section{Methodology}

This project included a literature review of applicable theory, both qualitative and quantitative research elements, and strategies for a landscape design. The literature review established the theoretical and practical foundations for the work, and covered topics including: complex adaptive systems, 
socioecological resilience, social cohesion, ecosystem services, green infrastructure, and place attachment. For the sake of brevity, this paper will focus upon the original research conducted for the project. The original research $-\mathrm{a}$ community survey and a series of expert interviews - established the local context for the work, a baseline for presence of social cohesion, and a framing for the applicability of the ten prominent characteristics of resilient communities. Taken together, the application of design responded to the collective voice and needs of the community and provides a set of goals, phases, strategies for design as a framework that have been adopted as the foundation for plans for implementation of an urban blueway.

\section{The local context}

Vancouver, British Columbia, Canada, like most modern cities, is home to several buried streams. St George Street is a residential right-of-way that seeks to reinvigorate the ecological heritage of the stream that once followed its northsouth orientation. This corridor has become known as the St George's Rainway. The remaining flows from the St George Creek travel northward beneath the street and are piped as part of the storm sewer main buried there. A study of the storm sewer catchment and contours creating this corridor reveals a pipe subbasin that roughly encompasses approximately 54 hectares, or one-quarter of the area of Vancouver neighbourhood of Mount Pleasant. This is home to the study site of, and contributing namesake to, this work.

Over the span of three years, community members of Mount Pleasant have grown public awareness of the stream and of the potential for the nineblock residential section of the street. They have activated other members of the community and have engaged members of City staff and of local organizations to become more involved with the transformation. During these three years, a document titled, "From Connections to Engagement: Pathways to a More Caring and Involved Citizenry" [3] was published. It contained survey findings published by the Vancouver Foundation that identified a strong need for both strengthening of social cohesion throughout Vancouver. Of the findings, those key to note are as follows: "1. Metro Vancouver can be a hard place to make friends; 2. Our neighbourhood connections are cordial, but weak; 3. Many people in Metro Vancouver are retreating from community life; [and] 4. There are limits to how people see diversity as an opportunity to forge meaningful connections" [4, p. 7].

The survey was the first step in working towards building more connected communities within Metro Vancouver and is the benchmark for the St George Rainway Project. The survey and its findings ask of projects like the Rainway to "include a dimension that builds bridges and brings together people who may not have had the opportunity to work together before" [4, p. 40].

The Rainway offers an opportunity to be a demonstration project for the City of Vancouver where the city and the community act as collaborators with design, construction, and maintenance of the project. Having successfully daylighted portions of a stream in East Vancouver, known as Still Creek, and implemented 
sustainable street initiatives like Crown Street, the City of Vancouver has set a precedent for investing in the health of urban streams [5,6]. Green infrastructure at the time of this study was, however, not a practice yet adapted by the City. Subsequently, stormwater retains its characterization as a waste product and not as a resource. This simple reframing of the perception of water in the urban environment is where the discussion of resilience, framed by green infrastructure, can begin.

\title{
4 The characteristics of resilient communities
}

There is a synergy between the nesting of ecology, society, economy, and socioecological systems, or the "integrated concept of humans-in-nature" [7]. Urban resilience must be considered for the entire system and not only its social and ecological subsystems. Further, if one is to use resilience as a benchmark for development, it is essential to identify the state of the system whose maintenance is preferred - the resilience of what - as well as the outside forces that may act upon it - the resilience to what - that might transform its state into one altogether different [8].

In the case of the Rainway, the proposed design utilizes offers the resilience of social cohesion to enable the implementation and maintenance of green infrastructure by members of the community. This will establish a network of living organisms - plants and soil microorganisms - to provide the capacity for ecosystem services. Subsequently, the local urban form is meant to embody resilience to the perturbations brought by a changing climate. More directly, the design provides opportunities for increased social and ecosystem health to subsequently increase the robustness of the community to address future challenges.

A review of the current body of literature analyzing socioecological resilience produces a series of common threads that can begin to help characterize its measure in the context of urban development. Ten in particular are most commonly represented throughout research literature [9]. The resulting list offers indicators that can provide insight into engagement opportunities between communities and the impacts from stressors such as climate change. The ten primary characteristics of resilient communities provide a framework for where to begin to envision resilient communities. They are characterized by Bahadur et al. [9] as:

\author{
1. A high degree of diversity \\ (Key descriptors: heterogeneous, multidisciplinary, multifunctional) \\ 2. Effective governance and institutions \\ (Key descriptors: decentralized, linked, accountable) \\ 3. Acceptance of change and uncertainty \\ (Key descriptors: flexible, adaptive, testable) \\ 4. Non-equilibrium system dynamics \\ (Key descriptors: energy-conserving, ecologically-balanced) \\ 5. Community engagement and participation \\ (Key descriptors: local, sense of ownership, place-based)
}


6. Capacity for preparedness and planning

(Key descriptors: redundant, yielding, projecting)

7. A high degree of equity

(Key descriptors: accessible, unbiased, egalitarian)

8. Presence of social capital

(Key descriptors: participating, supportive, trusting, engaged, connected)

9. Capacity for learning

(Key descriptors: creative, active learning, knowledge retention)

10. A cross-scalar perspective

(Key descriptors: cross-temporal, cross-spacial, cascading).

The series of expert interviews and applications of design offered by this study provide contextual definitions and a means of activation for each characteristic.

\section{Surveys, social cohesion, and social capital}

Findings from two surveys were used for this work. The first were published by the Vancouver Foundation [4] to measure the relative social cohesion throughout the metro region of Vancouver. The second was a survey created specifically for this work which focused on people from the community ultimately responsible for the life of the St George's Rainway. It established an understanding of how social cohesion present in Mount Pleasant compares to the entire Metro Vancouver region by offering the same line of questioning as the parent survey.

By measures of the comparative study with the parent survey, Mount Pleasant better embodied a majority of the eight domains of social capital [10] than did Metro Vancouver. This was determined by comparing the answers to the questions with the greatest weight as determined by the algorithm created to process the findings from the parent survey. Each of the answers were tallied as "greater," "equal," or "less than" with factorial scoring. The result was a simplified means to compare the results of each survey. The findings demonstrated how, for every one answer Metro Vancouver was superior, Mount Pleasant answered favorably with nearly three. Consequently, this offered a rationale for support to come from the City of Vancouver, where those projects identified by a sustained grassroots initiative garner political attention.

A finer grained examination of the survey results offered direct evidence of a greater existence of participation, supporting networks, trust, and belonging was highlighted in the survey. Further, the additional questions present in the Mount Pleasant survey, illustrated the existence of collective norms and values, associational activity, and empowerment. Safety, the remaining domain, was not directly shown to exist, yet its existence was not disproven. The intention with the strategies for design for the St George Rainway is to phase its development and implementation, coupled with a community-managed maintenance program, to build upon the bonding and bridging, and to exponentially grow social capital.

Social cohesion is founded upon social capital. It manifests itself in community first, and not in a top-down fashion [10]. Consequently, the public realm offers the best opportunity for a collaboration between city and 
community to improve social capital. However, in some cases, such as those where a neighbourhood block watch, grown from a strong presence of social capital, begins to grow distrust of other groups, the bottom-up approach could lead to an eventual decline in social capital [11]. Social capital should therefore be viewed as "important not for its own sake, but for what one does with it, or can attain by it, as with other forms of capital" [10, p. 2141]. In the case of Mount Pleasant, it would benefit the City to harness the positive nature of the social capital that exists within the neighbourhood. It could do so by supporting the St George Rainway with policy and actions that: 1. offer opportunities for participation in the decision-making process, 2. build networks of organizations with common purpose, 3. foster new and existing synergies and connections between individuals and groups, 4. promote interests of the community, and 5. help with growing the community's sense of place through design intervention within the public realm.

It is within the public realm where people can grow their relationships with one another and with place. The higher level of social cohesion in Mount Pleasant relative to Metro Vancouver could be rooted in the makeup of individuals who, at the time, resided there; it could be due to the predominant typology of residential buildings with porches fronted by tree-lined sidewalk streets [12]; or it could respond to the groups and institutions that exist in Mount Pleasant and promote various domains of social capital. Regardless of the drivers, the setting and people of Mount Pleasant was shown to offer an opportunity.

The purpose of the comparative analysis of the two surveys was to provide a baseline of rationale to support or disagree with an implementation of the St George Rainway based upon its location. By this measure, the Mount Pleasant survey accomplished its goal. However, it should be noted that the survey could have been deemed successful if the results demonstrated a lower level of social cohesion present within Mount Pleasant. In such a case, the argument could have been flipped to state need, rather than ease, as the driver of opportunity.

\section{Interviews, archetypes, and transference}

A deeper and more nuanced understanding of how to grow social cohesion can be garnered through the voices of experts and stakeholders. Eight interviewees were chosen and characterized as archetypes to focus the discussion of resilient communities in the context of Mount Pleasant and greater Vancouver. Archetypes have been used in both ecological and socioecological applications of resilience $[13,14]$. They can act as surrogates or proxies that have been developed from a combination of theory and case studies to help test and hypothesize impacts of various scenarios.

The ethnographic lens that each of the interviewees offered also exist between generalized and case-specific reasoning. In turn, they grow one's understanding of the framing for this study and the potential form it will take. The shared perspectives through the lenses of archetypes allows for a transference of ideas and insightful correlation with the theoretical basis for resilient communities. 
Each interview began with a discussion of the interviewee's perspective of social cohesion in the context of Mount Pleasant, but none traced an identical path of exploration and conviction. The archetypes grew from a grounded theory process for each interview that did not begin with hypotheses, but rather enabled the development of themes and archetypes to grow from the coding of the interviews $[15,16]$. The resulting archetypes and their offerings of leadership were those of:

1. The Exemplar

(Offering leadership through example and offering sound precedent)

2. The Advocate

(Offering leadership through local context and political involvement)

3. The Expert

(Offering leadership through promotion of learning from broad experience)

4. The Manager

(Offering leadership through bureaucratic temperament and a balanced bias)

5. The Connector

(Offering leadership through ability to bridge social division with relationships)

6. The Champions

(Offering leadership through embodiment of attachment to place)

7. The Longview

(Offering leadership through transcendence of temporal and physical scales)

8. The Visionary

(Offering leadership through connections between narrative and place).

The goal of creating these profiles was to provide a transferrable means for application of the ten characteristics of resilient communities. As metaphors and symbols are used to imbue a sense of universality to stories, archetypes have been used for their similar functionality. The ten primary characteristics of resilient communities are described in the literature in a fashion that promotes similar universality to each. Thus, each could be applied to a range of challenges, people, and locales, regardless of the context. Viewing each insight through the eyes of an interviewee offers a local context to the characteristics; a broader transference, when viewed through the lens of their corresponding archetypes, can, in turn, present themselves in contexts outside the City of Vancouver.

\section{Strategies for design}

Two principles guided the strategies for design: 1. Produce the foundations for the provision of urban ecosystem services using green infrastructure; and 2. Propose the Rainway to support opportunities for direct community involvement with labour, maintenance, and stewardship that engage each of the ten characteristics of resilient communities. In response to these principles, the schematic design was structured by: goals, phases, and strategies for design. The goals were defined by a list of eight ecosystem services common to urban areas; the design was split into phasing that offers an incremental approach in 
line with the fostering monetary, social, and ecological capital; the phases were comprised of six strategies actualized through projects in the public realm. These strategies included such components of green infrastructure as rain gardens, fruit-bearing plants, permeable laneways, downspout disconnections, rainwater harvesting, community cisterns, pocket wetlands, and ultimately, a constructed stream.

\subsection{An overview}

Projects involving green infrastructure and a neighbourhood-scale landscape require capital in the form of budgeted tax revenue that, at the time of this work, did not exist according to the City of Vancouver [17]. However, a breakdown of the capital required for such a project as the St George Rainway can be viewed in terms of design hours, materials (living and nonliving), and labour hours originating in part from sources outside the scope of the City's budget. When viewed through this lens, feasibility and viability of the project become more aligned. With the time needed to do such things as build awareness and consensus, fundraise, and harness in-kind expertise and labour, phasing of the schematic design becomes integral.

While each strategy for design of the Rainway has been conceived to build upon those that took place prior to itself, attempts to abide by strict linearity do not reflect the makeup of complex adaptive systems. A less linear, more adaptive approach to phasing would involve freedoms to simultaneously run several strategies at once. However, to ensure stakeholders, residents, and volunteers are maintaining a unified vision through their actions, a recommendation was given that that public visioning charrettes be deemed essential, and held at annual or bi-annual intervals to retain solidarity and cohesiveness with vision.

The original vision - traditional daylighting of the creek - was found to require a costly engineering feat. Currently, the stream runs through a pipe over $4 \mathrm{~m}$ beneath the surface of the street. With an average width of $12 \mathrm{~m}$, the entire St George right-of-way would require, at best, a 1:1 slope if it was to be daylighted while retaining half the street as functional roadway. If it is to be more than walled channel, such a slope would make a stream inaccessible by both humans and the sun, thus defeating many of the goals of a blueway.

In Vancouver, storm sewer pipes that have already been disconnected from the combined sewer system flow directly into culverted streams and daylighted waterways, and then into larger collecting bodies. The City of Vancouver is currently working towards an entirely separated system [18] to manage its combined sewer overflow (CSO) events. Storm sewer separation is commonly considered by most North American municipalities as a key component to improving waterway health in the face of large storm events.

Currently, the Vancouver neighbourhood of Mount Pleasant still functions with a combined system, where all flows, storm and waste, are directed to the nearest treatment plant. Separation is a noble means to address CSO events and increased treatment demands, but would pose a new challenge for the smaller events responsible for the stormwater flows created by the majority of the 
rainfall [19, 20]. The polluted runoff from these smaller events, currently receiving primary treatment prior to its discharge into the Pacific Ocean, will, in a separated system, enter untreated directly into the local waterways of Vancouver. The efforts to clean the waterways that have resulted in an increase of aquatic biodiversity in recent years would likely be reversed as a result.

\subsection{Resilience characteristics emulated}

The strategies for design of the Rainway demonstrate their potential for emulation of the ten characteristics of resilient communities through activation.

To offer an understanding of how each characteristic is activated by the strategies is the following list:

\subsubsection{A high degree of diversity}

A high degree of diversity was emulated through each of the strategies by offering additional stormwater management and treatment tools to establish a more heterogenous system than what is offered through grey infrastructure. This and a provision of food assets, each offered through the diversity of green infrastructure mechanisms, provide identical functioning for the Rainway and its stewards. Maintaining a high degree of diversity amongst stakeholders will help with adaptation to changes and effects upon social systems, as it will bring with it a multidisciplinary set of knowledge and expertise. Regarding the physical Rainway, this characteristic can provide a network of physical components like rain gardens that can act individually, while enhancing the overall functionality of green infrastructure in Mount Pleasant when linked together.

\subsubsection{Effective governance and institutions}

Though necessary for each strategy, effective governance and institutions was shown to lack thorough demonstration on behalf of the City of Vancouver. Consequently, the City needs to lead through example and allow for shared accountability with projects in the public realm for the Rainway to be realized. This could be achieved by decentralizing decision-making and governance for the Rainway, while holding partner stakeholders accountable through the monitoring of each of its components. Lastly, it is essential to this characteristic to maintain a network of stakeholders who are connected by heterogeneity and autonomy enough to avoid cascading failures throughout the project.

\subsubsection{Acceptance of change and uncertainty}

Acceptance of change and uncertainty was applicable to any of the strategies as long as they maintain malleability and flexibility and are able to adapt to needs and challenges as they shift. In the spirit of the ability of pilot initiatives to adapt their implementation with greater feasibility and viability for future conditions, the framing of the Rainway as a pilot project would enable the City to embrace adaptive management and test alternative methods of stormwater management at 
a larger scale. With this characteristic, policy should be viewed as questions, not answers, and where the strategies are the means to test adaptive solutions.

\subsubsection{Non-equilibrium system dynamics}

The characteristic of non-equilibrium system dynamics can be achieved through harnessing natural system processes to provide sources of capital that in turn drive ecologically-balanced strategies. As an example, the Rainway proposes more ecologically-balanced approaches to water consumption, treatment of stormwater runoff, and to stormwater regulation by borrowing processes and assets from nature to complete the work. The greater the share of green over grey infrastructure can embody, the stronger it exemplifies this characteristic.

\subsubsection{Community engagement and participation}

As a characteristic directly related to the presence and of social cohesion and growing a sense of ownership and a sense of place, community engagement and participation is evident in each of the strategies and the localized stewardship opportunities they have to offer. Each offers potential for community involvement with installation, monitoring, and maintenance of aspects to several strategy components. Additionally, they offer the potential for collaborative design of any element that exists in the public realm. For the Rainway to embody this characteristic, community engagement and participation and the sense of ownership it can deliver is essential.

\subsubsection{Capacity for preparedness and planning}

The characteristic of the capacity for preparedness and planning is best characterized by the ability to embrace the longview and give weight to preparing for greatest risk with a redundancy in strategies. This therefore requires actions to speak louder than words and for plans to exist strictly to lay the groundwork for activation of strategies. For each strategy to embody preparedness, they need to offer redundancies. These redundancies should be inter-strategical in that strategies should consist of several linked components, such as rain gardens or pocket wetlands, that could maintain functionality even when one component fails or is brought offline. Additionally, the redundancies should include linkages between strategies that increase during the growth of Rainway until the ultimate constructed stream is realized.

\subsubsection{A high degree of equity}

Equity is characterized by allowing the social and natural capital of strategies to flow without bias. A high degree of equity is emulated through the democratic access to the social and natural capital provided through construction and maintenance of rain gardens and food assets as well as through the construction and maintenance of pocket wetlands and a prioritization of selected streets for people over motorized vehicles. Additionally, an insurance of equally distribution access to natural and social capital needs to not only transcend current cultural, racial, demographic, and social boundaries, its provision should be sustained across generations and for the life of the Rainway. 


\subsubsection{Presence of social capital}

Social cohesion is built upon the presence of social capital, which, by the measures of the survey results, has a strong presence in Mount Pleasant. The domains of social capital offer the means by which residents can build bonds and bridges to establish relationships that in turn satisfy their needs. Closely related to characteristics associated with participation and decision making, social capital is only as strong as the networks that foster it. Therefore, every strategy for design of the Rainway requires elements of empowerment, participation, associational activity, and sense of belonging that can be gleaned through community participation with construction, maintenance, and stewardship.

\subsubsection{Capacity for learning}

Having the capacity for learning requires the ability to practice adaptive management and to constantly be able to project current information to future scenarios. This can be established through the provision of feedback loops so that active learning can thrive and aid in avoiding systemic failures. A method to create the necessary positive feedback loops is through the retention of collective knowledge gained from past initiatives. Retained recirculated knowledge, when viewed critically, can create a foundation for the future strategy of creating a constructed stream and for other such projects throughout the City.

\subsubsection{A cross-scalar perspective}

A cross-scalar perspective is demonstrated by the ability to recognize scales that transcend size and time and provide the reminder that all actions within systems can have cascading effects. Socially, the cross-spacial and cascading impact this strategy could have is directly linked to the levels of participation and replication that exist within the components of each strategy. Ecologically, the impacts of the noted strategies would be cross-temporal, cross-spacial, and would be potentially cascading. The combination of cisterns, pocket wetlands, a constructed stream, and so on - would impact water supply and stormwater loads and would cascade to impact the larger hydrologic systems to which the Rainway is linked. What began with a street mural could become a constructed stream that could inspire a growth of green infrastructure City-wide.

\section{Conclusion}

The St George Creek lies beneath a residential street. However, if expressions of it are to be brought to the surface, its water could be transformed from waste product to resource, enabling the St George Rainway project to bisect the three concentric rings of sustainable development - ecology, society, and economy and offer much more to the city. The findings of this project demonstrate how the implementation of green infrastructure can offer social cohesion another dimension beyond the ecosystem services it traditionally offers. Further, it posits that the voluntary engagement involved in the physical transformation 
of one's community can simultaneously provide opportunity for increasing the bonding and bridging within it. Therefore, social cohesion both increases, and can be increased by, the implementation of green infrastructure. Furthermore, social cohesion can create a positive feedback loop in its ability to reciprocally improve the establishment and success of the green infrastructure from where it grew.

With hopes of becoming the developed world's greenest city by the year 2020, Vancouver has recently put forth a series of goals and targets beyond the goal of clean water. A struggle with regard to some of the goals is the need for policy to reflect the level of ambition embodied in the goals. Of the ten characteristics of resilient communities, acceptance of uncertainty and change best demonstrates how one might look at the role of policy differently in this case. If policy could instead be viewed as questions, then testing solutions might more readily be accepted. This project offers how the mission of these pursuits of the City could be achieved simultaneously through the implementation of green infrastructure along a 9-block residential street. Green infrastructure in its various forms can strengthen socioecological resilience and not only reduce the burden on storm sewers, but return some of its water to the surface to be cleaned, celebrated, and cherished as a resource for all types of life. Resilient cities are built upon collections of resilient communities. Such places are what is needed to help plan for the inevitable, yet unpredictable challenges of our future.

\section{References}

[1] Chan, J., et al. Reconsidering Social Cohesion: Developing a Definition and Analytical Framework For Empirical Research. Social Indicators Research, 75, 273-302, 2006.

[2] U.S. EPA, http://water.epa.gov/infrastructure/greeninfrastructure/index.cfm

[3] DiPaula, A., Lau, G., and Herrin, L. From connections to engagement: pathways to a more caring and involved citizenry, 2012.

[4] Vancouver Foundation. Connections and engagement: A survey of metro Vancouver, 2012.

[5] City of Vancouver Community Services. Still creek rehabilitation and enhancement study, 2002.

[6] City of Vancouver. Crown Street: Sustainable streetscapes \& fish habitat enhancement project, 2006.

[7] Berkes, F., Folke, C., \& Colding, J. Linking social and ecological systems: management practices and social mechanisms for building resilience. Cambridge: Cambridge University Press, 2000.

[8] Carpenter, S. R., Brock, W. A., Ludwig, D., \& Twain, M. Collapse, learning, and renewal. Panarchy: Understanding transformations in human and natural systems, 173, 2001.

[9] Bahadur, A. V., Ibrahim, M., \& Tanner, T. Characterising resilience: unpacking the concept for tackling climate change and development. Climate and Development, (ahead-of-print), 1-11, 2013. 
[10] Forrest, R., \& Kearns, A. Social cohesion, social capital and the neighbourhood. Urban studies, 38(12), 2125-2143, 2001.

[11] Fukuyama, F. The great disruption: Human nature and the reconstitution of social order. London: Profile Books, 1999.

[12] Katz, P., Scully, V. J., \& Bressi, T. W. The new urbanism: Toward an architecture of community (Vol. 10). New York: McGraw-Hill, 1994.

[13] Bennett, E. M., Cumming, G. S., \& Peterson, G. D. A systems model approach to determining resilience surrogates for case studies. Ecosystems, 8(8), 945-957, 2005.

[14] Eisenack, K., Lüdeke, M., \& Kropp, J. Construction of archetypes as a formal method to analyze social ecological systems. In Proceedings of the Institutional Dimensions of Global Environmental Change Synthesis Conference. Bali (Vol. 6, No. 9), 2006.

[15] Charmaz, K. Constructing grounded theory: A practical guide through qualitative analysis. Pine Forge Press, 2006.

[16] Emerson, R. M., Fretz, R. I., \& Shaw, L. L. Writing ethnographic fieldnotes. University of Chicago Press, 2011.

[17] City of Vancouver. 2013 capital and operating budget, 2013.

[18] City of Vancouver, http://vancouver.ca/home-property-development /separating-sewage-from-rainwater.aspx

[19] Sansalone, J. J., \& Buchberger, S. G. Partitioning and first flush of metals in urban roadway storm water. Journal of Environmental engineering, 123(2), 134-143, 1997.

[20] Watson, D., \& Adams, M. Design for Flooding: architecture, landscape, and urban design for resilience to climate change. John Wiley \& Sons, 2010 . 